\title{
Hysterectomy for dysfunctional uterine bleeding in women with previous tubal sterilization
}

\author{
Hethyshi Ranganna*, Nirmala Shivlingiaha
}

\author{
Department of Obstetrics \& Gynecology, Kempegowda Institute of Medical Sciences and Research (KIMS), \\ Bangalore, Karnataka, India
}

Received: 14 February 2014

Accepted: 22 February 2014

\section{*Correspondence:}

Dr. Hethyshi Ranganna,

E-mail: hethyshi@gmail.com

(C) 2014 Ranganna $\mathrm{H}$ et al. This is an open-access article distributed under the terms of the Creative Commons Attribution Non-Commercial License, which permits unrestricted non-commercial use, distribution, and reproduction in any medium, provided the original work is properly cited.

\begin{abstract}
Background: Post tubal ligation syndrome has been a topic of debate with various studies concluding contradictory results. Hysterectomy can be considered as a continuum of the post ligation syndrome due to prolonged menstrual complaints. The present study was done to evaluate any association of tubal sterilization with hysterectomy in patients presenting with dysfunctional uterine bleeding.

Methods: The study was conducted in a medical college hospital. Analysis of case files of patients who had undergone hysterectomy for dysfunctional uterine bleeding between May 2012 - May 2013 was done to note the history of prior tubal sterilization. Patients with fibroid uterus, adenomyosis, hypothyroidism, endometrial polyp, cervical polyp and those who had a hysterectomy for nonmenstrual complaints were excluded.

Results: 322 patients were hysterectomised during the study period. Among them only 36 patients had a hysterectomy purely for dysfunctional uterine bleeding. Out of the 36 patients, 33 patients (90.9\%) had undergone prior tubal sterilization. Hysterectomy was done after a mean duration of $19.31 \pm 5.35$ years after tubal sterilization. The mean age at onset of menorrhagia was at $42.05 \pm 4.71$ years.

Conclusions: Tubal sterilization is a risk factor for future hysterectomy in patients with dysfunctional uterine bleeding.
\end{abstract}

Keywords: Tubal sterilization, Post tubal ligation syndrome, Hysterectomy, Dysfunctional uterine bleeding

\section{INTRODUCTION}

Population explosion especially in the developing countries is a burning issue. Family planning methods are a boon to tackle this issue. Tubal sterilization which is a permanent method of family planning is one of the most popular contraceptive choices in the majority of developing countries. ${ }^{1}$ In India, there has been a steady increase in the percentage of women adopting tubal sterilization as a method of family planning. ${ }^{2}$ In $2005-$ 2006 , the country's contraceptive prevalence was $56 \%$, and $66 \%$ of users reported female sterilization as their method. $^{2}$ The increasing acceptance of tubal sterilization warrants evaluation of the safety and long term consequences of this procedure. Post tubal ligation syndrome is one such concern. Menstrual dysfunction associated with this syndrome ultimately leading to hysterectomy could be a possibility. The present study was done to evaluate the role of prior tubal sterilization in patients who were hysterectomised for complaints of dysfunctional uterine bleeding.

\section{METHODS}

The study was conducted in a tertiary care centre affiliated to a medical college. Records of patients who were hysterectomised for complaints of menstrual disorders during a period of one year from May 2012 May 2013 were reviewed. Patients with hypothyroidism, fibroid uterus, endometriosis, endocervical polyp, 
endometrial polyp were excluded. Patients in whom hysterectomy was done for non-menstrual complaints like prolapse uterus, ovarian tumors were also excluded. Case files of the selected patients were retrieved from the record section and relevant details were noted. The collected data was analyzed by SPSS statistical software (version 11). Chi-square test, student t test and ANOVA were used for comparison. $\mathrm{P}$ value of 0.05 or less was considered as statistically significant.

\section{RESULTS}

There were a total of 322 hysterectomies done during the study period of 12 months. Only 36 patients among the 322 operated fulfilled the inclusion criteria. The baseline characteristics of the 36 patients are shown in Table 1. Out of the 36 patients, $30(90.90 \%)$ had a prior tubal sterilization, $3(9.09 \%)$ patients were not tubectomised and information regarding contraception was not available in 3 patients. There was no significant relation between tubectomised and non tubectomised patients with regard to the duration of onset of menorrhagia $(\mathrm{p}=0.713)$. Out of 30 patients who were tubectomised, 10 patients $(33.3 \%)$ had undergone laparoscopic tubal occlusion and 5 patients (16.6\%) had an abdominal tubectomy. There was no significant relation with type of tubal sterilization and duration of onset of complaints $(\mathrm{p}=0.063)$. Information regarding the type of tubectomy was not available in 15 patients.

Table 1: Baseline characteristics.

\begin{tabular}{|ll|}
\hline Baseline characteristics & Value \\
\hline Mean age $(n=36)$ & $43.75 \pm 4.16$ years \\
\hline Mean parity $(n=36)$ & $2.69 \pm 0.93$ \\
\hline $\begin{array}{l}\text { Mean age at tubal sterilisation } \\
(n=30)\end{array}$ & $24.48 \pm 4.8$ years \\
\hline $\begin{array}{l}\text { Mean duration between tubal } \\
\text { sterilisation and hysterectomy } \\
(n=29)\end{array}$ & $19.31 \pm 5.35$ years \\
\hline $\begin{array}{l}\text { Mean duration from onset of } \\
\text { menorrhagia ( } n=36)\end{array}$ & $20.44 \pm 35.68$ months \\
\hline $\begin{array}{l}\text { Mean duration between } \\
\text { sterilisation and onset of } \\
\text { menorrhagia }(n=30)\end{array}$ & $17.57 \pm 7.11$ years \\
\hline $\begin{array}{l}\text { Mean age at onset of } \\
\text { menorrhagia }(n=36)\end{array}$ & $42.05 \pm 4.71$ years \\
\hline
\end{tabular}

\section{DISCUSSION}

Long term health consequences following tubal sterilization have to be evaluated considering the increasing acceptance of this procedure. Post tubal ligation syndrome refers to a constellation of estrogen deficiency symptoms arising due to the altered blood supply to the ovaries, resulting from the tubal manipulation during sterilization. ${ }^{3,4}$ The existence of this syndrome was in debate when studies done on mid luteal hormone serum levels suggested no major changes in ovarian function following tubal sterilisation. ${ }^{5}$ Also no difference was seen in a study done to compare the hormonal change following tubal sterilization by Pomeroy method with Uchida technique which is free of the risk of compromise of ovarian circulation. ${ }^{6}$ Menstrual irregularities is one of the manifestations of the post tubal ligation syndrome with varied presentation of oligomenorrhea, dysmenorrhea, premenstrual distress and menorrhagia.

Earlier studies reported increased incidence of menorrhagia following tubal sterilization. ${ }^{7-9}$ A review study done in 1998 by Gentile et al. concluded that tubal sterilization is not associated with an increased risk of menstrual dysfunction, dysmenorrhea, or increased premenstrual distress in women who undergo the procedure after age 30 years. ${ }^{10}$ The review also concluded that there may be some increased risk for younger women, although they do not appear to undergo significant hormonal changes. They also concluded that, failure to control for age, parity, obesity, previous contraceptive use, interval since sterilization, or type of sterilization may have affected the results in the earlier studies and studies that have controlled for these variables had not reported any significant change, except in women who undergo sterilization between 20 and 29 years of age. A recent analysis of the CREST data in 2000 prospectively examined menstrual patterns of 9,514 women for 5 years after interval tubal sterilization and compared them with those of women whose partners underwent vasectomy. The study found that women who underwent sterilization were no more likely than the control group to report persistent changes in their menstrual cycle length or inter-menstrual bleeding and also the method of tubal occlusion did not have a significant impact on the findings. ${ }^{11}$ In 2005 Shobeiri et al. in a cross sectional study found no difference in the occurrence of menstrual irregularities in 112 patients with history of Pomeroy tubal ligation and 288 women with no previous tubal ligation. ${ }^{12}$

Hysterectomy due to prolonged menstrual complaints is an entity at the other end of the spectrum of post tubal ligation syndrome. ${ }^{9,13,14}$ In 1993 Goldhaber et al. analyzed hospital data of 39502 sterilized women with 40505 comparison women matched on age, race, parity and interval since birth. ${ }^{15}$ Sterilized women were significantly more likely than were comparison women to undergo hysterectomy $(\mathrm{RR}=1.35,95 \% \mathrm{CI} 1.26-1.44)$, especially for diagnoses of menstrual dysfunction and pelvic pain $(\mathrm{RR}=1.88,95 \% \mathrm{CI} 1.65-2.13)$. Relative risks were highest for women who were young on the reference date $(\mathrm{RR}=2.45,95 \%$ CI $1.79-3.36$ for women aged 20-24 years), but declined steadily as age increased $(\mathrm{RR}=0.96,95 \%$ CI $0.72-1.28$ for women aged $40-49$ years). In all age groups, relative risks were significantly above 1.00 after 7 years of follow-up. In our study the mean age of the patients in years was $43.75 \pm 4.16$ and hence risk comparison in relation to younger age group cannot be made. 
In 1997, Hillis SD et al. used the data from U S Collaborative for review of sterilization working group (CREST) study which was a multicentric prospective cohort study involving 10,698 patients to examine the long term probability of hysterectomy. ${ }^{16}$ They found that although women with gynecologic disorders before tubal sterilization were at greater risk of hysterectomy during the 14 years after sterilization than were women without these disorders, the majority of sterilized women in both categories did not undergo subsequent hysterectomy. The risk was found to persist across all ages and methods. In the present study also there was no significant difference in the duration of onset of complaints in patients with an abdominal tubectomy and those with laparoscopic sterilization. In our study sterilization was done 19.31 \pm 5.35 years before hysterectomy and the mean duration of onset of complaints in months was $20.44 \pm 35.68$ prior to hysterectomy. So our patients did not have any menstrual complaints at the time of tubal sterilization. However majority of the hysterectomised patients were sterilized.

In order to avoid the results being affected the present study was designed to include only those patients with dysfunctional uterine bleeding with all other causes for menorrhagia both gynecological and hormonal being excluded. Only one study in the past has been done on the same lines. It was done by Sanam et al. in Oman in 2012. They had retrospectively analyzed medical records of 67 patients who had a hysterectomy for abnormal uterine bleeding. ${ }^{17}$ They found that there was no significant difference in hysterectomy between those who were tubectomised $(28.36 \%)$ and those who were not tubectomised (71.64\%). But in our study $90.09 \%$ of the patients were tubectomised.

The CREST study found that there was no increase in menstrual irregularities up to 5 years following tubal sterilization but there was an increased risk of hysterectomy 14 years after tubal sterilization. The patients in our study developed complaints of menorrhagia about $17.57 \pm 7.11$ years after tubal sterilization and subsequently hysterectomy $19.31 \pm 5.35$ years following tubal sterilization. So there could be a latent biological effect of tubal sterilization that can lead to hysterectomy. However the mean age of women at onset of menstrual complaints was $43.75 \pm 4.16$ years, which is the age when there is increased incidence of menstrual abnormalities and also the age at which hysterectomy is preferred. Hence studies with larger sample size are warranted to differentiate if the menstrual abnormalities were a consequence of prior tubal sterilization or simply that there is an increased incidence of menstrual irregularities at that point of time in their lifetime. The need for such studies delineating the long term consequences of tubal sterilization is more in the developing countries like India where tubal sterilization is the choice of family planning in majority of the eligible couples.

\section{CONCLUSIONS}

Hysterectomy can be a long term consequence of tubal sterilization due to menstrual irregularities. The age of the patients in this study was the age when there is increased incidence of menstrual irregularities. Hence further studies are needed to clarify if the menstrual irregularities are a consequence of tubal sterilization or simply an age related incidence due to which they are prone to hysterectomy.

\section{Funding: No funding sources}

Conflict of interest: None declared

Ethical approval: The study was approved by the institutional ethics committee

\section{REFERENCES}

1. International Institute for Population Sciences (IIPS) and Macro International. National Family Health Survey (NFHS-3). India, Mumbai. 2005-6;1:1-24.

2. United Nations Population Division, Department of Economic and Social Affairs. Levels and trends of contraceptive use, 1998. Available at: http://www.un.org/esa/population/pubsarchive/wcu/f wcu.htm. Accessed 15 January 2004.

3. Alvarez-Sanchez F, et al. Pituitary-ovarian function after tubal ligation. Fertil Steril. 1981 Nov;36:606-9.

4. Cattanach J. Oestrogen deficiency after tubal ligation. Lancet. 1985 Apr;1(8433):847-9.

5. Garza-Flores $\mathbf{J}$, et al. Assessment of luteal function after surgical tubal sterilization. Advances in Contraception. 1991;7(4):371-7.

6. Alvarez F, Faundes A, Brache V, Tejada AS, Segal S. Prospective study of the pituitary-ovarian function after tubal sterilization by the Pomeroy or Uchida techniques. Fertil Steril. 1989 Apr;51(4):604-8.

7. Wilcox LW, et al. Menstrual function after tubal sterilization. American Journal of Epidemiology. 1994;135:1368-81.

8. Tappan JG. Kroener tubal ligation in perspective. Am J Obstet Gynecol. 1973 Apr;115(8):1053-7.

9. Boyd EM. Post-tubal-sterilization syndrome. J R Coll Gen Pract. 1987 Jun;37(299):272.

10. Gentile GP, Kaufman SC, Helbig DW. Is there any evidence for a post-tubal sterilization syndrome? Fertil Steril. 1998 Feb;69(2):179-86.

11. Peterson HB, Jeng G, Folger SG, Hillis SA, Marchbanks PA, Wilcox LS. U. S. Collaborative Review of Sterilization Working Group. The risk of menstrual abnormalities after tubal sterilization. U.S. Collaborative Review of Sterilization Working Group. N Engl J Med. 2000 Dec;343(23):1681-7.

12. Shobeiri MJ, Atashkhoii S. The risk of menstrual abnormalities after tubal sterilization: a case control study. BMC Womens Health. 2005 May;5(1):5.

13. Muldoon MJ. Gynaecological illness after sterilization. Br Med J. 1972;1:84-5.

14. Stergachis A, Shy KK, Grothaus LC, Wagner EH, Hecht JA, Anderson G, Normand EH, Raboud J. 
Tubal sterilization and the long-term risk of hysterectomy. JAMA. 1990 Dec;264(22):2893-8.

15. Goldhaber MK, Armstrong MA, Golditch IM, Sheehe PR, Petitti DB, Friedman GD. Long-term risk of hysterectomy among 80,007 sterilized and comparison women at Kaiser Permanente, 19711987. Am J Epidemiol. 1993 Oct;138(7):508-21.

16. Hillis SD, Marchbanks PA, Tylor LR, Peterson HB. Tubal sterilization and long-term risk of hysterectomy: findings from the United States collaborative review of sterilization. The U. S. Collaborative Review of Sterilization Working Group. Obstet Gynecol. 1997 Apr;89(4):609-14.

17. Moradan S, Gorbani R. Is Previous Tubal Ligation a Risk Factor for Hysterectomy because of Abnormal Uterine Bleeding? Oman Med J. 2012 Jul;27(4):3268 .

DOI: $10.5455 / 2320-1770 . i j r \operatorname{cog} 20140341$

Cite this article as: Ranganna $\mathrm{H}$, Shivlingiaha $\mathrm{N}$. Hysterectomy for dysfunctional uterine bleeding in women with previous tubal sterilization. Int $\mathbf{J}$ Reprod Contracept Obstet Gynecol 2014;3:204-7. 